\title{
Epidemiology, species composition and genetic diversity of tetra- and octonucleated Entamoeba spp. in different Brazilian biomes
}

Deiviane Aparecida Calegar ${ }^{1 *}$ (D) , Kerla Joeline Lima Monteiro ${ }^{2}$, Polyanna Araújo Alves Bacelar ${ }^{1,2}$, Brenda Bulsara Costa Evangelista 1,2, Mayron Morais Almeida', Jéssica Pereira dos Santos ${ }^{1,2}$, Márcio Neves Boia ${ }^{3}$, Beatriz Coronato-Nunes ${ }^{1,4}$, Lauren Hubert Jaeger ${ }^{1,5+}$ and Filipe Anibal Carvalho-Costa ${ }^{1 \dagger}$

\begin{abstract}
Background: Entamoeba species harbored by humans have different degrees of pathogenicity. The present study explores the intra- and interspecific diversity, phylogenetic relationships, prevalence and distribution of tetra- and octonucleated cyst-producing Entamoeba in different Brazilian regions.

Methods: Cross-sectional studies were performed to collect fecal samples $(n=1728)$ and sociodemographic data in communities located in four Brazilian biomes: Atlantic Forest, Caatinga, Cerrado, and Amazon. Fecal samples were subjected to molecular analysis by partial small subunit ribosomal DNA sequencing (SSU rDNA) and phylogenetic analysis.
\end{abstract}

Results: Light microscopy analysis revealed that tetranucleated cysts were found in all the studied biomes. The highest positivity rates were observed in the age group 6-10 years (23.21\%). For octonucleated cysts, positivity rates ranged from 1 to $55.1 \%$. Sixty SSU rDNA Entamoeba sequences were obtained, and four different species were identified: the octonucleated E. coli, and the tetranucleated E. histolytica, E. dispar, and E. hartmanni. Novel haplotypes $(n=32)$ were characterized; however, new ribosomal lineages were not identified. The Entamoeba coli ST1 subtype predominated in Atlantic Forest and Caatinga, and the ST2 subtype was predominant in the Amazon biome. E. histolytica was detected only in the Amazon biome. In phylogenetic trees, sequences were grouped in two groups, the first containing uni- and tetranucleated and the second containing uni- and octonucleated cyst-producing Entamoeba species. Molecular diversity indexes revealed a high interspecific diversity for tetra- and octonucleated Entamoeba spp. $(H \pm S D=0.9625 \pm 0.0126)$. The intraspecific diversity varied according to species or subtype: E. dispar and E. histolytica showed lower diversity than E. coli subtypes ST1 and ST2 and E. hartmanni.

Conclusions: Tetra- and octonucleated cyst-producing Entamoeba are endemic in the studied communities; $E$. histolytica was found in a low proportion and only in the Amazon biome. With regard to E. coli, subtype ST2 was

\footnotetext{
*Correspondence: deivianecalegar@gmail.com

†Lauren Hubert Jaeger and Filipe Anibal Carvalho-Costa contributed equally to this work

${ }^{1}$ Laboratório de Epidemiologia e Sistemática Molecular, Instituto Oswaldo Cruz, Fundação Oswaldo Cruz, Rio de Janeiro, RJ, Brazil

Full list of author information is available at the end of the article
}

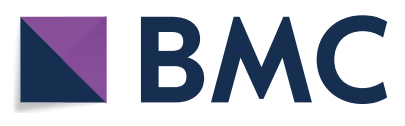

(c) The Author(s) 2021. This article is licensed under a Creative Commons Attribution 4.0 International License, which permits use, sharing, adaptation, distribution and reproduction in any medium or format, as long as you give appropriate credit to the original author(s) and the source, provide a link to the Creative Commons licence, and indicate if changes were made. The images or other third party material in this article are included in the article's Creative Commons licence, unless indicated otherwise in a credit line to the material. If material is not included in the article's Creative Commons licence and your intended use is not permitted by statutory regulation or exceeds the permitted use, you will need to obtain permission directly from the copyright holder. To view a copy of this licence, visit http://creativeco mmons.org/licenses/by/4.0/. The Creative Commons Public Domain Dedication waiver (http://creativecommons.org/publicdomain/ zero/1.0/) applies to the data made available in this article, unless otherwise stated in a credit line to the data. 
predominant in the Amazon biome. The molecular epidemiology of Entamoeba spp. is a field to be further explored and provides information with important implications for public health.

Keywords: Entamoeba genus, Molecular epidemiology, Small subunit ribosomal DNA, Intra- and interspecific diversity

\section{Background}

Entamoeba species harbored by the human digestive tract have different degrees of pathogenicity and impact on public health [1]. Although some species are considered commensal and non-pathogenic, E. histolytica can cause serious, life-threatening, and invasive infections such as amoebic dysentery and liver abscess [2]. Entamoeba histolytica produces tetranucleated cysts which are indistinguishable from those produced by E. dispar. The similarity of the cysts led to the adoption of the nomenclature E. histolytica/E. dispar complex, which also includes Entamoeba moshkovskii, another tetranucleated cyst-producing species. Although $E$. dispar and E. moshkovskii are considered to have less pathogenic potential [3], they have occasionally been associated with invasive disease $[4,5]$. These findings have led to the need for further studies to assess the epidemiology of indistinguishable tetranucleated amoebas [3]. Entamoeba species that parasitize other animals can also infect humans [6].

Entamoeba coli, which are considered a commensal and harmless organism, produce octonucleated cysts and can be considered a marker of inadequate sanitary conditions, denoting greater exposure to other fecal pathogens. Recently, however, potential pathogenicity has been attributed to this species. Mexican children infected with $E$. coli have higher levels of stool leucocytes than uninfected children, pointing to the possibility of intestinal inflammatory activity triggered by this organism $[7,8]$. Additionally, considerable intraspecific genetic variability has been demonstrated for $E$. coli, which can be divided into two subtypes: E. coli ST1 and E. coli ST2 [9].

Typically, the clinical detection of Entamoeba species in fecal samples has been performed through light microscopy. However, the overlap of morphological characteristics between some species and the morphological and size variation in structures are limiting factors for microscopic species-specific diagnosis [10]. The implementation of molecular tools for Entamoeba species characterization has enabled a greater understanding of their taxonomy, phylogenetic relationships and epidemiology [11].

Despite recent advances, the proportion of households without sanitation systems in many regions of Brazil remains high. The country has great socioeconomic, environmental and demographic diversity, and appropriate access to drinking water is restricted in many communities. Similarly, peri-urban and urban communities in large Brazilian cities in more industrialized states frequently have poor sanitation infrastructure. In the present study, we explored the species composition, the inter- and intraspecific genetic diversity and phylogenetic relationships, and the prevalence and distribution of Entamoeba species infecting populations living in different Brazilian biomes.

\section{Methods}

\section{Description of study area and population, study design} and sampling

Communities from cities located in four Brazilian biomes were selected: Cachoeiras de Macacu (CAM) in the state of Rio de Janeiro (Atlantic Forest biome), Teresina (TER) and São João do Piauí (SJPI) in Piauí (Cerrado and Caatinga biomes, respectively), and Santa Isabel do Rio Negro (SIRN) in Amazonas and Bagre (BAG) in Pará (Amazon biome) (Fig. 1). In the five municipalities, the studied communities had precarious access to drinking water and poor sanitation systems, to varying degrees and for distinct reasons. Table 1 shows the socio-environmental and demographic characteristics of each municipality and the number of individuals included in each one. These regions differ with respect to climate, proportion of the population living in poverty and human development index, among other parameters. Cross-sectional studies were carried out in the included areas to collect fecal samples and sociodemographic data. Entamoeba spp. fecal samples were identified as positive using parasitological methods (Ritchie's modified ethyl acetate centrifugation) [12].

\section{DNA extraction, polymerase chain reaction (PCR) and DNA sequencing}

Fecal samples positive on light microscopy were subjected to molecular analyses for species characterization and phylogenetic studies. In addition, some Entamoeba spp.-negative samples on microscopy were selected, randomly or when another individual from the same household was positive, to be tested by PCR. This was performed in order to improve the number of DNA sequences for genetic analyses. Genomic DNA was extracted from $200 \mu \mathrm{l}$ of the sedimented fecal material using the ZR Fungal/Bacterial DNA MiniPrep ${ }^{\mathrm{TM}}$ extraction kit (Zymo Research, Irvine, CA, USA). PCR was 


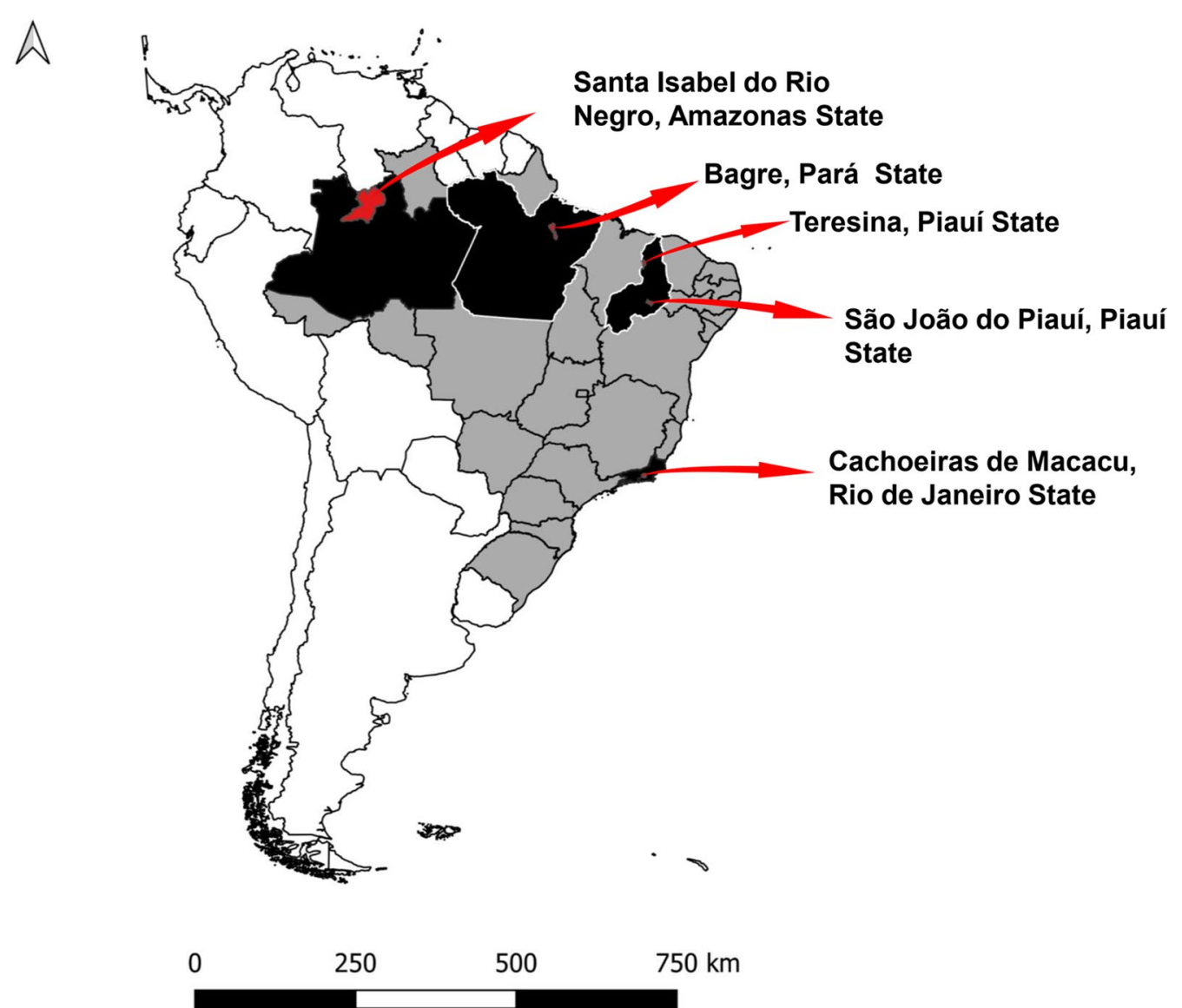

Fig. 1 Map of the studied areas in Brazil. The map was created using Google Earth Pro

performed using the Platinum Taq DNA Polymerase kit (Invitrogen, Waltham, MA, USA), with a final volume of $50 \mu \mathrm{l}$. The small subunit rRNA gene locus (SSU rDNA) of Entamoeba spp. (550 base pairs [bp]) was targeted for amplification, as described in Verweij et al. [13]. Amplification conditions were as follows: each deoxynucleoside triphosphate at $200 \mathrm{mM}, 25 \mathrm{pmol}$ of each specific primer, 10X PCR buffer, $1 \mathrm{U}$ of Taq DNA Polymerase, and $5 \mu \mathrm{l}$ of the DNA sample. The thermal cycling conditions were as follows: initial denaturation of $5 \mathrm{~min}$ at $94{ }^{\circ} \mathrm{C}, 35$ cycles of $30 \mathrm{~s}$ at $94{ }^{\circ} \mathrm{C}, 30 \mathrm{~s}$ at $55^{\circ} \mathrm{C}$, and $30 \mathrm{~s}$ at $72{ }^{\circ} \mathrm{C}$; and final extension of $2 \mathrm{~min}$ at $72^{\circ} \mathrm{C}$. The PCR products were purified with polyethylene glycol (PEG) [14] and sequenced using the BigDye Terminator v3.1 kit (Applied Biosystems, Foster City, CA, USA) in an ABI 3730 automated DNA sequencer (Applied Biosystems).

\section{Data analysis}

The obtained sequences were edited and analyzed using BioEdit version 7.2.5 software [15]. The Basic Local Alignment Search Tool (BLASTn; NCBI https://www. ncbi.nlm.nih.gov/) was used to verify similarity with
Entamoeba species. The obtained sequences were deposited in GenBank under accession numbers MW026735MW026794. BioEdit version 7.2.5 [15] was used to align and cut the sequences into equal fragments (542 bp). Phylogenetic inferences were performed using Molecular Evolutionary Genetics Analysis (MEGA) version 7.0.20 software [16]. The maximum likelihood (ML) and neighbor joining (NJ) methods were applied. The substitution model for the data set was chosen using the Bayesian information criterion (BIC) in MEGA version 7.0.20 software [16]. According to the lower BIC score, the Tamura 3-parameter model (T92) was chosen. Branch support was provided by bootstrapping with 1000 replications. Entamoeba spp. orthologous sequences $(n=46)$ were used to construct an alignment using the BLASTn tool against the Nucleotide Collection (nr/nt) database (https://www.ncbi.nlm.nih.gov/nucleotide/) (Additional file 1: Table S1). The reference sequences were selected to be representative of the genus. Sequences with degenerate bases were not included.

A median-joining (MJ) haplotype network was constructed in Network version 10.1.0.0 software [17] (www. 
Table 1 Sampling, sociodemographic and environmental characteristics of distinct study areas

\begin{tabular}{|c|c|c|c|c|c|}
\hline \multirow[t]{3}{*}{ Characteristic } & \multicolumn{5}{|l|}{ Biome } \\
\hline & \multicolumn{2}{|l|}{ Amazon } & \multicolumn{2}{|c|}{ Cerrado and Caatinga } & \multirow{2}{*}{$\begin{array}{l}\text { Atlantic forest } \\
\text { Cachoeiras de Macacu (RJ) }\end{array}$} \\
\hline & $\begin{array}{l}\text { Santa Isabel do Rio Negro } \\
\text { (AM) }\end{array}$ & Bagre (PA) & Teresina (PI) & São João do Piauí (PI) & \\
\hline Population & 22.404 & 30.673 & 864.845 & 20.601 & 58.937 \\
\hline Human development index & 0.479 & 0.471 & 0.751 & 0.645 & 0.700 \\
\hline Gini index & 0.35 & 0.37 & 0.50 & 0.45 & 0.45 \\
\hline Year of study & 2011 & 2020 & 2017 & 2018 & 2018 \\
\hline $\begin{array}{l}\text { Localization of districts } \\
\text { included }\end{array}$ & Urban & Urban & Rural & Rural & Urban and rural \\
\hline Fecal samples & 392 & 362 & 298 & 131 & 545 \\
\hline \multicolumn{6}{|l|}{ Income (MPCHI*, USD**) } \\
\hline$\leq 45$ & $302(77 \%)$ & $209(57.7 \%)$ & $153(51.4 \%)$ & $67(51.1 \%)$ & $192(35.2 \%)$ \\
\hline$>45$ & $90(23 \%)$ & $163(44.9 \%)$ & $145(48.6 \%)$ & $64(48.9 \%)$ & $290(53.2 \%)$ \\
\hline Data not available & - & - & - & - & $63(11.6 \%)$ \\
\hline Water supply & $\begin{array}{l}\text { Negro River and artesian } \\
\text { wells }\end{array}$ & $\begin{array}{l}\text { Furo Santa Maria } \\
\text { River (Baía de } \\
\text { Marajó) }\end{array}$ & Artesian wells & $\begin{array}{l}\text { Artesian wells and } \\
\text { water stored in } \\
\text { cistern }\end{array}$ & $\begin{array}{l}\text { Macacu River and artesian } \\
\text { wells }\end{array}$ \\
\hline$\%$ open evacuation & - & 142/362 (39\%) & $106 / 298(35.5 \%)$ & 63/131 (48\%) & - \\
\hline \multicolumn{6}{|l|}{ Gender } \\
\hline Male & 207 & 188 & 147 & 69 & 284 \\
\hline Female & 185 & 174 & 151 & 62 & 261 \\
\hline \multicolumn{6}{|l|}{ Age group (years) } \\
\hline $0-2$ & 87 & 80 & 11 & 7 & 99 \\
\hline $3-5$ & 108 & 83 & 15 & 7 & 120 \\
\hline $6-10$ & 142 & 135 & 29 & 14 & 184 \\
\hline $11-15$ & 49 & 62 & 35 & 27 & 235 \\
\hline$>15$ & - & - & 207 & 76 & 5 \\
\hline Data not available & 6 & - & 1 & - & 43 \\
\hline
\end{tabular}

AM Amazonas, PA Pará, PI Piauí, RJ Rio de Janeiro

${ }^{*} \mathrm{MPCHI}-$ monthly per capita house income, ${ }^{* *}$ USD $1=\mathrm{BRL} 4$

fluxusengineering.com), with the input file previously prepared in DnaSP (DNA Sequence Polymorphism) version 6 software [18]. Diversity indexes of tetra- and octonucleated Entamoeba populations were determined using the pairwise distance in Arlequin version 3.5.2.2 software [19]. The pairwise $F_{\text {st }}$ (fixation index) value was tested in all populations using Arlequin version 3.5.2.2 software [19] to estimate the extent of genetic differentiation among populations with a significance of 1000 random permutations.

\section{Results}

\section{Study population}

Figure 2 presents the detection rates for tetra- and octonucleated Entamoeba cysts in fecal microscopic examinations in distinct age groups and settings. In the Amazon and Atlantic Forest biomes, tetranucleated cysts were found in fecal samples from children up to 2 years of age, with positivity rates ranging from 3.8 to $10.3 \%$, respectively. In these biomes, one of the highest rates was found in the age group of $11-15$ years, reaching $26.5 \%$. In the four studied states, octonucleated cysts were detected through microscopy in $1-20.6 \%$ of children up to 2 years of age, and $10.8-49.3 \%$ of children aged $6-10$ years.

\section{Molecular epidemiology and genetic diversity of Entamoeba spp.}

A total of 60 SSU rDNA Entamoeba spp. sequences (542 bp) were obtained from fecal samples. The BLAST analyses revealed four different Entamoeba species: $E$. coli $(n=32)$, E. dispar $(n=18)$, E. hartmanni $(n=8)$ and $E$. histolytica $(n=2)$ (Table 2). With regard to the $E$. histolytica/E. dispar complex, the Amazon biome presented the greatest species diversity. In Piauí, only $E$. dispar was identified. With respect to E. coli, ST1 predominated in Rio de Janeiro and Piauí, and ST2 was predominant in Amazonian states (Amazonas and Pará). Figure 3 displays the ML and NJ trees inferred from uni-, 


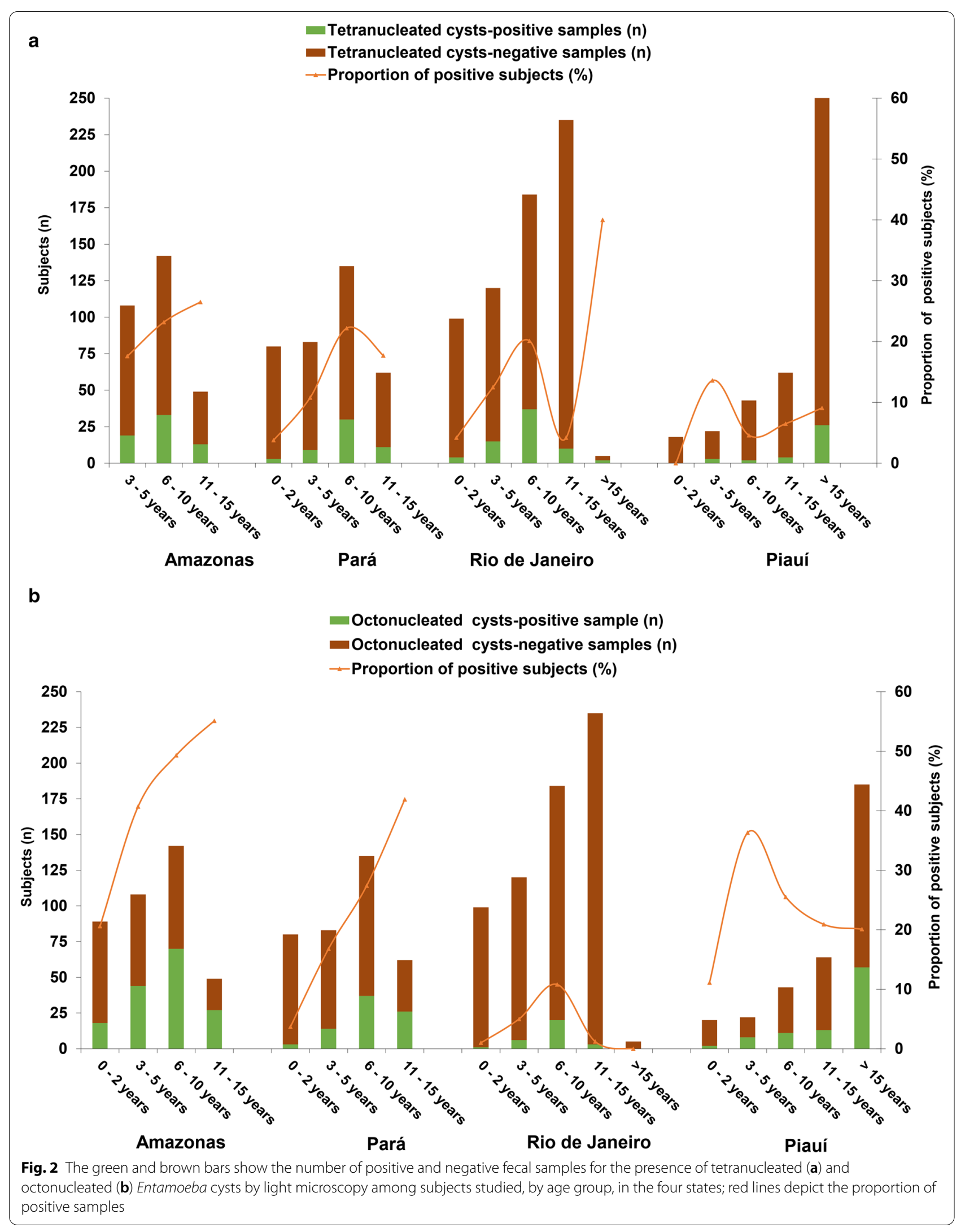


Table 2 Molecular diversity indexes of tetra- and octonucleated cyst-producing Entamoeba based on SSU rDNA locus (542 bp, $n=89$ )

\begin{tabular}{|c|c|c|c|c|c|c|c|}
\hline \multirow[t]{2}{*}{ Species $(N)$} & \multirow[t]{2}{*}{ Region $(N)$} & \multicolumn{6}{|l|}{ Statistics } \\
\hline & & $H \pm S D$ & $\begin{array}{l}\text { No. of } \\
\text { haplotypes }\end{array}$ & $\begin{array}{l}\text { No. of } \\
\text { polymorphic } \\
\text { sites }\end{array}$ & $\begin{array}{l}\text { No. of } \\
\text { substitutions }\end{array}$ & No. of transitions & $\begin{array}{l}\text { No. of } \\
\text { transversions }\end{array}$ \\
\hline \multirow[t]{9}{*}{ E. coli (38) } & All ST1 (16) & $0.816 \pm 0.095$ & 9 & 45 & 44 & 27 & 17 \\
\hline & Brazil (12) & $0.772 \pm 0.127$ & 7 & 44 & 44 & 27 & 17 \\
\hline & $\mathrm{BAG}+\mathrm{SIRN}(5)$ & $0.700 \pm 0.218$ & 3 & 5 & 5 & 3 & 2 \\
\hline & TER (2) & $1.0000 \pm 0.5000$ & 2 & 1 & 1 & 1 & 0 \\
\hline & SJPI (3) & $0.6667 \pm 0.3143$ & 2 & 4 & 4 & 2 & 2 \\
\hline & CAM (2) & $1.000 \pm 0.500$ & 2 & 7 & 7 & 3 & 4 \\
\hline & All ST2 (22) & $0.952 \pm 0.029$ & 15 & 52 & 57 & 26 & 31 \\
\hline & Brazil (20) & $0.957 \pm 0.028$ & 14 & 52 & 57 & 26 & 31 \\
\hline & $\mathrm{BAG}+\mathrm{SIRN}(19)$ & $0.959 \pm 0.030$ & 14 & 52 & 57 & 26 & 31 \\
\hline \multirow[t]{5}{*}{ Entamoeba dispar (21) } & All (21) & $0.500 \pm 0.132$ & 7 & 26 & 22 & 16 & 6 \\
\hline & Asia (3) & $0.000 \pm 0.000$ & 1 & 0 & 0 & 0 & 0 \\
\hline & Brazil (18) & $0.568 \pm 0.137$ & 7 & 26 & 22 & 16 & 6 \\
\hline & $\operatorname{TER}(2)$ & $0.625 \pm 0.139$ & 7 & 26 & 22 & 16 & 6 \\
\hline & $\mathrm{BAG}+\mathrm{SIRN}(16)$ & $0.000 \pm 0.000$ & 1 & 0 & 0 & 0 & 0 \\
\hline \multirow[t]{2}{*}{ E. hartmanni (10) } & All (10) & $0.977 \pm 0.054$ & 9 & 28 & 24 & 16 & 8 \\
\hline & Brazil (8) & $0.964 \pm 0.077$ & 7 & 28 & 24 & 16 & 8 \\
\hline \multirow[t]{3}{*}{ E. histolytica (6) } & All (6) & $0.533 \pm 0.172$ & 2 & 4 & 2 & 1 & 1 \\
\hline & North America (3) & $0.000 \pm 0.000$ & 1 & 0 & 0 & 0 & 0 \\
\hline & Brazil (2) & $0.000 \pm 0.000$ & 1 & 0 & 0 & 0 & 0 \\
\hline All* (89) & & $0.9625 \pm 0.0126$ & 55 & 353 & 272 & 203 & 199 \\
\hline
\end{tabular}

$H \pm$ SD: gene diversity \pm standard deviation. All*: E. dispar, E. histolytica, E. hartmanni, E. coli, Entamoeba sp., E. moshkovskii, E. ecuadoriensis, E. bangladeshi, E. nuttalli, E. muris, E. terrapinae, E. insolita, E. invadens, Entamoeba RL7, Entamoeba RL10, Entamoeba RL5, Entamoeba RL6. Further details for reference strains can be found in Additional file 1: Table S1. Bold indicates sequences obtained in this study (Brazil). BAG Bagre, CAM Cachoeiras de Macacu, SIRN Santa Isabel do Rio Negro, SJPI São João do Piauí, TER Teresina

tetra- and octonucleated Entamoeba spp. cysts, with a total of 106 Entamoeba SSU rDNA sequences $(n=60$ sequences from the present study plus 46 reference sequences). Two major groups were observed, the first one containing uni- and tetranucleated cyst-producing Entamoeba species, and the second containing Entamoeba species producing uni- and octonucleated cysts. The main differences between the two trees were as follows: (i) in the ML tree, E. moshkovskii was grouped in a single clade (Fig. 3a), while in the NJ tree it was grouped together with other tetranucleated cyst-producing Entamoeba species (Fig. 3b); and (ii) Entamoeba RL5, RL6 and $E$. insolita were grouped in a single clade on the NJ tree, while on the ML tree they were grouped close to $E$. hartmanni.

Among 28 samples containing tetranucleated Entamoeba cysts, only two were characterized as the pathogenic E. histolytica. The other 26 were identified as $E$. hartmanni or E. dispar. Entamoeba histolytica was identified only among isolates from the Amazon biome (Amazonas, $n=2$ ); E. dispar was identified in the Cerrado (Teresina, Piaui, $n=2$ ) and Amazon biomes (Pará, $n=10$, and Amazonas, $n=6)$. E. hartmanni was characterized only in the Amazon biome (Pará and Amazonas in five and three samples, respectively). No Entamoeba moshkovskii or uninucleated cyst-producing Entamoeba species were found.

Entamoeba coli was the species most commonly found $(n=32)$ and was present in all localities studied. Both $E$. coli subtypes ST1 $(n=12 ; 37.5 \%)$ and ST2 $(n=20 ; 62.5 \%)$ were identified. Subtype ST1 was described in all regions studied (Piauí, $n=5$; Rio de Janeiro, $n=2$; Amazonas, $n=3$; and Pará, $n=2$ ), while ST2 was found almost exclusively in the Amazon region (Amazonas, $n=9$ and Pará, $n=10$ ) (Fig. 4).

The MJ haplotype network based on tetra- and octonucleated cyst-producing Entamoeba showed a similar topology to the ML tree discriminating species or subtypes (Fig. 5). A total of 60 SSU rDNA sequences from the present study plus 29 reference sequences were distributed in 55 haplotypes. Thirty-six different haplotypes were identified in our sequences, and several new haplotypes were found. In E. coli ST1 and ST2, five and 13 new haplotypes were characterized, respectively. Entamoeba 


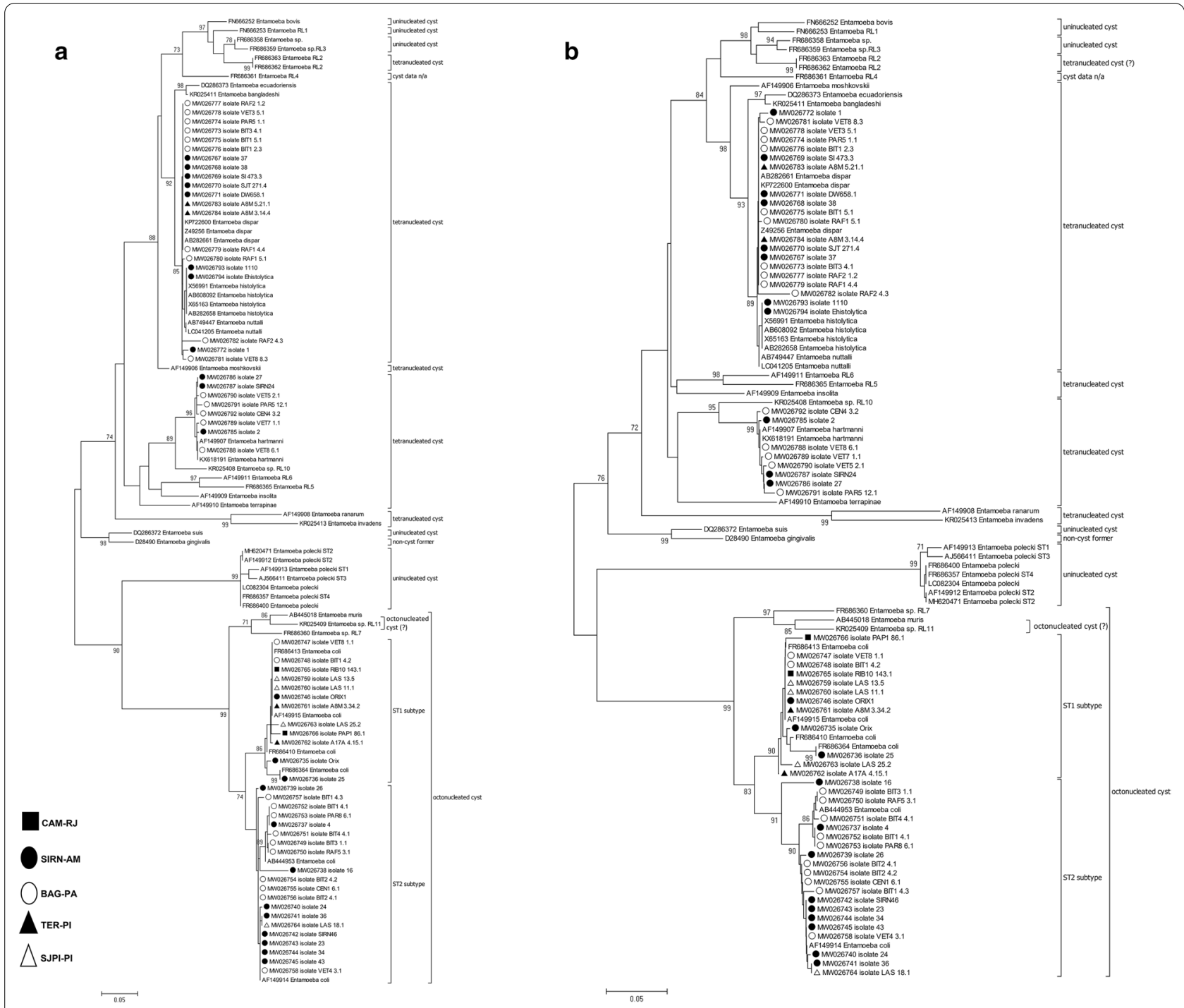

Fig. 3 a Maximum likelihood and $\mathbf{b}$ neighbor-joining trees inferred from uni-, tetra- and octonucleated cyst-producing Entamoeba spp. SSU rDNA locus (542 bp, $n=106$ ). Support for the branching order was determined b 1,000 bootstrap replicates, and only values $>70 \%$ are reported. The number of nuclei in the mature cyst are shown. BAG Bagre, CAM Cachoeiras de Macacu, SIRN Santa Isabel do Rio Negro, SJPI São João do Piauí, TER Teresina. GenBank accession numbers are indicated. Further details for reference strains can be found in Additional file 1: Table S1

hartmanni, E. dispar and E. histolytica had seven, six and one new haplotype, respectively. Entamoeba dispar and E. coli subtype ST1 presented a star-shaped haplotype network (Fig. 5), with a central and dominant haplotype. Interestingly, most of our samples belong to this ancestral haplotype.

Analysis of molecular diversity indexes revealed high interspecific diversity for tetra- and octonucleated Entamoeba spp., with $H \pm \mathrm{SD}=0.9625 \pm 0.0126$ and 353 polymorphic sites (Table 2). The intraspecific diversity varied according to species or subtype. Entamoeba dispar and $E$. histolytica showed lower intraspecific variability
$(H \pm \mathrm{SD}=0.500 \pm 0.132$ and $0.533 \pm 0.172$, respectively $)$ than $E$. coli subtypes ST1 and ST2 and E. hartmanni $(H$ $\pm \mathrm{SD}=0.816 \pm 0.095,0.952 \pm 0.029$, and $0.977 \pm 0.054$, respectively) (Table 2). The intraspecific variability of these two species was similar to the interspecific variability for the species. The $\mathrm{F}_{\text {st }}$ results corroborate the diversity analysis results (Additional file 2: Table S2). The $E$. dispar sequences from different Brazilian biomes showed low $F_{\text {st }}$ values, indicating no isolation between populations. For E. coli ST1 and ST2 sequences, even with high genetic variability, there was no evidence of significant 


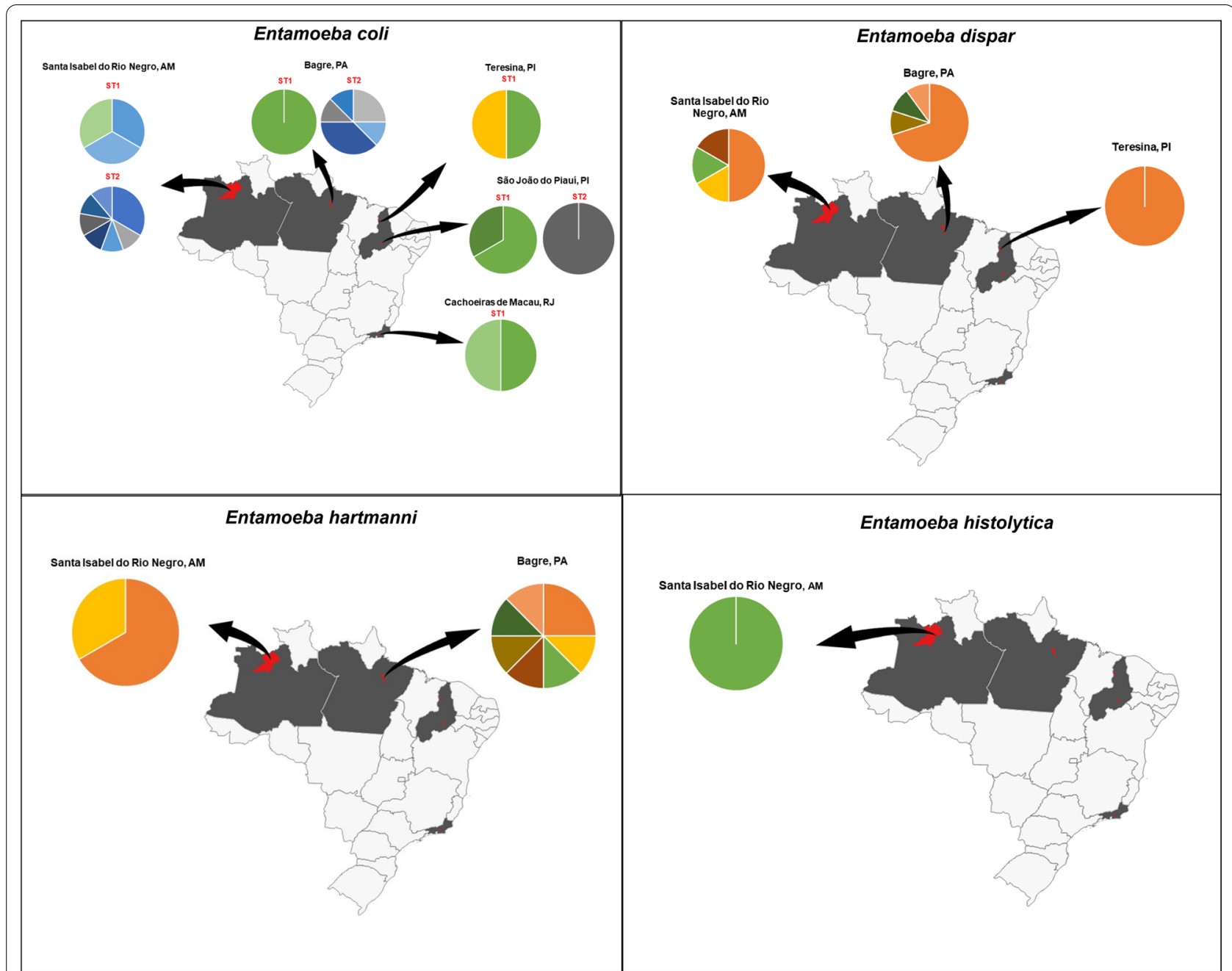

Fig. 4 Map of the haplotypes found by locality, Brazil. The colors in the graphs represent the diversity of haplotypes found for each species. The map was created using QGIS version 3.12.3

isolation between populations (Additional file 2: Table S2 and Fig. 5).

Tetra- and octonucleated cyst co-infections were identified by microscopy in $18.6 \%$ (72/387) of fecal samples. Of these, 39 samples were subjected to PCR. Overlapping peaks were not observed in the sequences, indicating failure to detect co-infections. Table 3 shows the results obtained by microscopy and PCR. All fecal samples collected ( $n=1728$ ) were subjected to the traditional parasitological technique (Ritchie's modified ethyl acetate centrifugation) and microscopy. It was not possible to perform PCR on all samples due to technical or logistical limitations. Two hundred and fifty-three samples were subjected to PCR. Of these, $65.3 \%$ (77/118) were positive for both techniques and 34.7\% (41/118) were PCR-positive and microscopy-negative (Table 3). Finally, 60 Entamoeba spp. sequences were successfully obtained (50.8\% of PCR amplifications), and many sequences from other organisms were identified, including fungi, bacteria, plants and other intestinal protozoa (Endolimax, Iodamoeba and Blastocystis genera) (data not shown).

\section{Discussion}

In the present study, we describe high positivity rates for infection by Entamoeba spp. in economically vulnerable communities with poor health infrastructure in different regions of Brazil. Amebiasis is a water- and food-borne disease with strong socio-environmental determinants, and its distribution is poverty-related and heterogeneous among human populations [20-22] and remains endemic in many Brazilian regions.

We characterized species and subtypes of Entamoeba spp. circulating in different communities. The interspecific variability of Entamoeba spp. based in SSU rDNA 


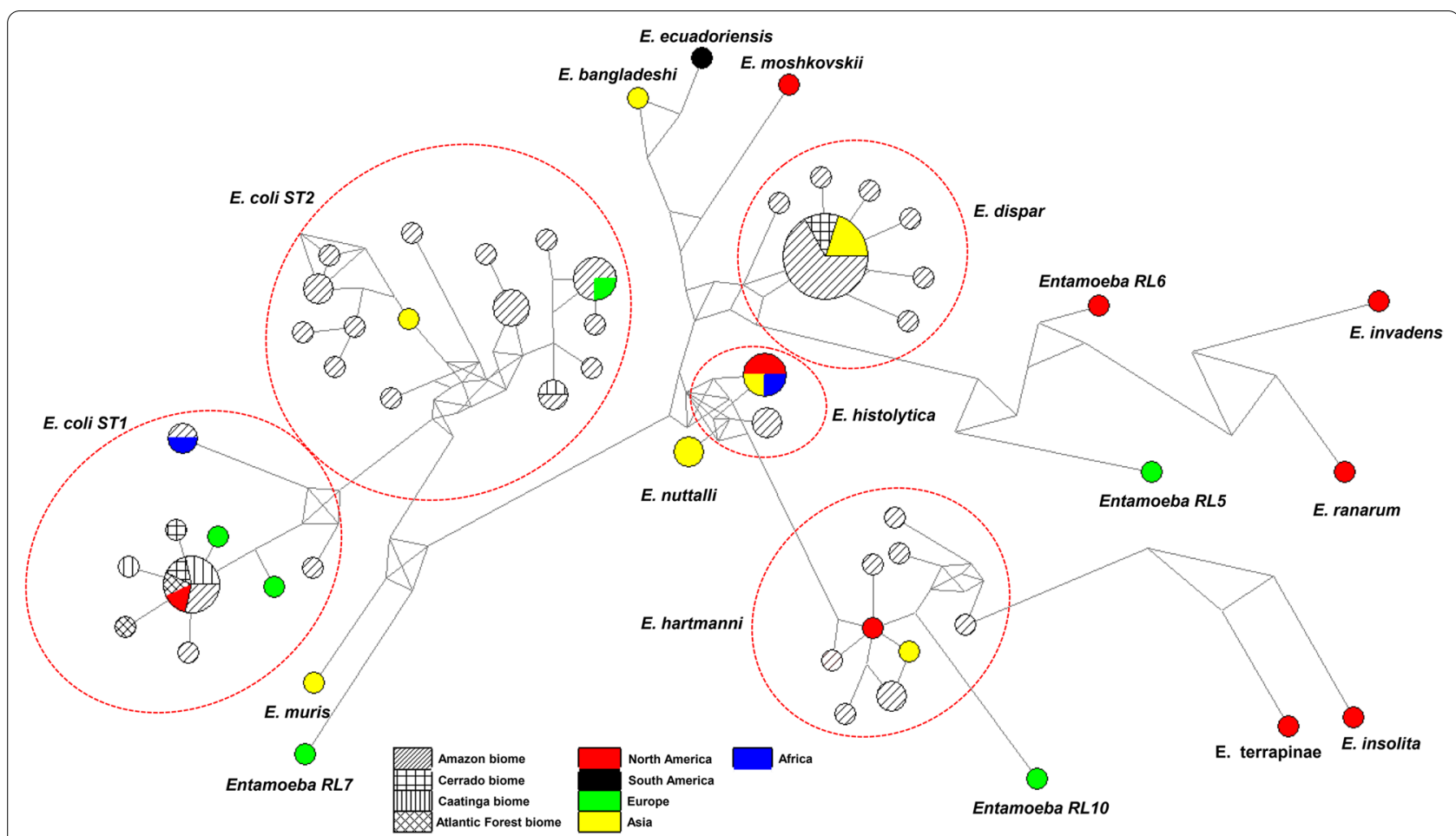

Fig. 5 Haplotype network based on SSU rDNA locus of tetra- and octonucleated cysts of Entamoeba $(542 \mathrm{bp}, n=89)$. Area of the circle is proportional to number of sequences

Table 3 Entamoeba spp. microscopy and PCR results in the present study

\begin{tabular}{|c|c|c|c|c|c|c|}
\hline \multirow[t]{2}{*}{ Biome/locality } & \multirow[t]{2}{*}{ Samples } & \multicolumn{5}{|l|}{ Result } \\
\hline & & $\begin{array}{l}\text { Microscopy-positive } \\
N(\%)\end{array}$ & $\begin{array}{l}\text { PCR-positive* } \\
N(\%)\end{array}$ & $\begin{array}{l}\text { Microscopy- } \\
\text { positive + PCR- } \\
\text { positive } \\
N(\%)\end{array}$ & $\begin{array}{l}\text { Microscopy- } \\
\text { negative + PCR- } \\
\text { positive } \\
N(\%)\end{array}$ & $\begin{array}{l}\text { Entamoeba } \\
\text { spp. sequences } \\
\text { obtained** } \\
N(\%)\end{array}$ \\
\hline \multicolumn{7}{|l|}{ Amazon } \\
\hline Santa Isabel do Rio Negro (AM) & 392 & $160 / 392(40.8)$ & $38 / 98(38.7)$ & $16 / 38(42.1)$ & 22/38 (57.9) & $23 / 38(60.5)$ \\
\hline Bagre (PA) & 362 & 65/362 (17.9) & $36 / 59(61)$ & $30 / 36(83.3)$ & $6 / 36(16.7)$ & $27 / 36(75)$ \\
\hline \multicolumn{7}{|l|}{ Caatinga and Cerrado } \\
\hline Teresina (PI) & 298 & $59 / 298(19.7)$ & $14 / 26(53.8)$ & 10/14 (71.4) & 4/14 (28.6) & $4 / 14(28.5)$ \\
\hline São João do Piauí (PI) & 131 & $31 / 131(23.6)$ & $16 / 33(48.4)$ & 13/16 (81.3) & $3 / 16(18.7)$ & $4 / 16(25)$ \\
\hline \multicolumn{7}{|l|}{ Atlantic Forest } \\
\hline Cachoeiras de Macacu (RJ) & 545 & $72 / 545(13.2)$ & 14/37 (37.8) & $8 / 14(57.1)$ & $6 / 14(42.9)$ & $2 / 14(14.2)$ \\
\hline Total & 1728 & 387/1728 (22.3) & $118 / 253(46.6)$ & 77/118 (65.3) & $41 / 118(34.7)$ & $60 / 118(50.8)$ \\
\hline
\end{tabular}

Only fecal samples positive on light microscopy were subjected to molecular analyses for species characterization and phylogenetic studies. Some Entamoeba spp. negative samples on microscopy were selected, randomly or when another individual from the same household was positive, to be tested on PCR. $A M$ Amazonas, $P A$ Pará, PI Piauí, $R J$ Rio de Janeiro. N: absolute number. (\%): percentage. *Includes microscopy positive and negative results. ${ }^{* *}$ Sequences from other organisms were also obtained, including fungi, bacteria, plants and other intestinal protozoa (Endolimax genus)

locus was high, $\mathrm{H}$ close to 1 . Our results draw attention to the characterization of new haplotypes for all Entamoeba species. Of the 36 haplotypes found, only four had already been described. These four haplotypes were in a central region of the haplotype network, indicating their ancestral nature, as in E. dispar and in E. coli ST1 and ST2. In addition, 14 new haplotypes described here originated from these ancestral haplotypes. Despite this, no new ribosomal lineages were identified. Among the members of the family Entamoebidae, the genus 
Entamoeba is the most well studied due to the pathogenic potential of certain species. In the phylogenetic trees generated in the present study, sequences were grouped into two groups for the Entamoeba genus, as in Stensvold et al. [9] and Jacob et al. [23]. However, some differences could be seen. Another limitation of the study is the fact that we obtained sequences of $542 \mathrm{bp}$, which corresponds to one third the size of the gene chosen for the analyses. This generated relatively low bootstrap values in some branches of the phylogenetic trees.

The most evident difference was that the uninucleated $E$. polecki species was grouped in the same group as the octonucleated E. coli, unlike Stensvold et al. [9], where it was grouped with the uni- and tetranucleated species. Our result is similar to the study by Jacob et al. [23], in which $E$. polecki shared a common ancestor with the octonucleated E. coli. Another evident difference was E. moshkovskii, which shared a common ancestor with uni- and tetranucleated in our ML tree. In contrast, in the NJ tree, this species shared a common ancestor with the tetranucleated species E. ecuadoriensis, E. dispar, E. histolytica, E. nuttalli and E. bangladeshi, as in Stensvold et al. [9] and Jacob et al. [23]. Additionally, E. hartmanni shared a common ancestor with E. insolita, E. terrapinae and Entamoeba RL5 and RL6 in the ML tree. In the NJ tree this species shared a common ancestor with $E$. terrapinae, as seen in Stensvold et al. [9]. Other small differences were seen when compared with Stensvold et al. [9] and Jacob et al. [23]. The differences observed between our study and previous studies can be explained by the fact that we did not use all the sequences available in GenBank, since we selected reference sequences without degenerate bases. Moreover, these results make us wonder whether the SSU rDNA locus or the "number of nuclei in the mature cyst" morphological character are suitable for the taxonomic classification of the Entamoeba genus. Apparently much still needs to be studied to understand the genetic complexity of members of this genus.

The main finding regarding tetranucleated cyst-producing Entamoeba species was the low proportion of E. histolytica found in the obtained sequences. Most sequences were characterized as E. dispar or E. hartmanni, considered nonpathogenic species. It is speculated that $E$. dispar and E. hartmanni are responsible for most infections that were previously considered to be associated with $E$. histolytica [3, 24, 25]. In fact, molecular epidemiological studies show that $E$. dispar is the species most commonly found among the tetranucleated cysts [21, 26-29]. Our results revealed that $E$. dispar presented a wider geographic distribution, whereas E. histolytica was identified only in the Amazon biome. Our results corroborate other studies conducted in Brazil, which have suggested that $E$. histolytica is more common in northern and northeastern Brazil and is less frequently detected in other regions $[26,30,31]$. However, we cannot rule out a sample bias and limitations in the PCR technique that could favor the amplification of one species over another.

In this study, we found only one haplotype for E. histolytica, and it was distinguished from the haplotype previously described in North America, Africa and Asia (X65163, E. histolytica HM-1:IMSS strain) [32-34]. In an overview of the diversity of Entamoeba histolytica by Zermeño and colleagues [35], they argue that although many haplotypes are found in only a single country, there are no lineages within the networks that may be related to a particular geographic region or infection outcome. These positive subjects in the present study had no symptoms. We must consider that most E. histolytica infections can be asymptomatic and that only $10 \%$ of those infected have symptoms [36-38].

The intraspecific variability of $E$. hartmanni was as high as the interspecific variability of the Entamoeba genus. In addition, among the eight sequences obtained from $E$. hartmanni, seven different haplotypes were found. Moreover, and all sequences were obtained in the Amazon biome. Only one haplotype obtained has been previously described in humans and nonhuman primates $(100 \%$ similarity to KX618191 and AF149907, respectively) [39, 40]. Previous studies have suggested low variability for $E$. hartmanni based on restriction fragment length polymorphism and SSU rDNA sequencing $[9,41]$. However, the real epidemiological significance of the high diversity found in the present study remains to be clarified.

The phylogenetic trees and MJ network revealed two main clusters for $E$. coli corresponding to the previously described subtypes ST1 and ST2 in Stensvold and colleagues [9]. In the present study, Entamoeba coli ST1 had a wider geographic distribution, being identified in all studied biomes, with the presence of five new haplotypes. Two previously described haplotypes were found, one isolated from humans in Nigeria (FR686364) [9] and the other from humans in the USA and nonhuman primates in Germany (AF149915 and FR686410, respectively) $[9,39]$. Entamoeba coli ST2 subtype was identified in the Caatinga and Amazon biomes, being the predominant subtype in the Amazon. Twenty sequences were obtained and 13 new haplotypes were described. Only one haplotype has been previously described, isolated from humans in England (AF149914) [41]. It is hypothesized that the ST1 subtype is more common than ST2 in humans [42], and ST2 was recently identified in wild nonhuman primates in Asia and Africa [43, 44]. It is intriguing to observe a large number of new $E$. coli ST2 subtypes in humans living in the Amazon rainforest, the habitat of great diversity of neotropical primates. 
We observed that $65.3 \%$ of the samples had a positive result with both techniques used (microscopy and PCR). Moreover, despite a reasonable number of PCRpositive samples $(n=118)$, we were only successful in sequencing and obtaining Entamoeba spp. SSU rDNA sequences in $50.8 \%$ of them. This makes us reflect on the limitations of the techniques used as well as of the fecal samples. Many factors can influence the success of the analysis, including low parasitic load in the sample and randomness in pipetting, unspecific PCR amplifications (multiple bands on the agarose gel), limitations in the PCR technique (primer binding, reaction), intrinsic limitations of the fecal samples (presence of microbiota and in different counts), and differences in the sensitivity of the techniques used. In addition, non-Entamoeba spp. sequences were obtained in this study, such as fungi or bacteria, which makes the analysis difficult and time-consuming.

The microscopy identified co-infections with octo- and tetranucleated cysts. In contrast, by direct nucleotide sequencing it was not possible to verify the presence of more than one species, and only a small amount of "background" was present in chromatograms. The species identified in the sequencing were related to the number of cysts observed under microscopy, in which more cysts represent more DNA available for PCR. The morphological similarity between $E$. histolytica and E. dispar, and the unusual large cysts of $E$. hartmanni, can also lead to misidentification [26], making microscopic analysis problematic for the diagnosis of non-symptomatic amebiasis.

As mentioned above, the communities included in the present study are situated in four different biomes with very distinct climates. Human populations in the Amazon, Caatinga and Cerrado regions have a higher prevalence of intestinal parasites, a higher incidence of diarrheal diseases and a lower proportion of the population with access to adequate sanitation and safe drinking water [45-48]. Although there are great differences in both the supply of drinking water and the water resource management strategies in these regions, in both there is a shortage of clean water for human consumption [47, 49].

In Brazil, intestinal parasitism control strategies target soil-transmitted helminths through mass albendazole administration. Moreover, the precarious conditions of sanitation and water management systems in some regions contributes to the current trend in the etiological profile of intestinal parasitism, characterized by the permanence of protozoan infections, with a reduction in the prevalence of soil-transmitted helminths [50-52]. Even though intestinal infections with soil-transmitted helminths are a major problem, affecting mainly children worldwide, estimates from the Global Burden of Disease Study indicate that other agents, including intestinal protozoa, are responsible for more than 6 million disability-adjusted life years (DALYs) [51].

\section{Conclusion}

Tetra- and octonucleated cyst-producing Entamoeba species are endemic in the studied communities, which represent low-income regions with nonexistent or insufficient sanitation systems. The pathogenic $E$. histolytica was found in a low proportion and only in the Amazon biome. Additionally, other tetranucleated species were commonly found in the studied regions. The distribution of Entamoeba species in Brazil is clinically important information, since many $E$. histolyticapositive parasitological examinations in fact represent infections with non-pathogenic species within the $E$. histolytica/E. dispar complex or E. hartmanni. Entamoeba coli subtypes present a geographically uneven distribution, with the ST2 subtype-commonly found in nonhuman primates-being predominant in the Amazon biome.

\section{Abbreviations}

ST1: Subtype 1; ST2: Subtype 2; CAM: Cachoeiras de Macacu; TER: Teresina; SJPI: São João do Piaú́; SIRN: Santa Isabel do Rio Negro; BAG: Bagre; PCR:

Polymerase chain reaction; SSU rDNA: Small subunit rRNA gene; ML: Maximum likelihood; NJ: Neighbor-joining; BIC: Bayesian information criterion; MJ: Median joining.

\section{Supplementary Information}

The online version contains supplementary material available at https://doi. org/10.1186/s13071-021-04672-y.

Additional file 1: Table S1. Entamoeba spp. reference strains used in the present study.

Additional file 2: Table S 2. Population pairwise Fst values based on SSU rDNA locus of tetra- and octonucleated cysts Entamoeba (542 bp, $n=89$ ).

\section{Acknowledgements}

We thank all the professionals involved, in particular communitarian health agents within the Family Health Strategy program of the municipality of Cachoeiras de Macacu-RJ/ Brazil. We thank also the administrative staff, Primary Health Care agents of Bagre-PA/Brazil for the support in field activities and Secretary of Health Paulo Ronaldo Rodrigues de Souza. The Program for Technological Development in Tools for Health-PDTIS/ FIOCRUZ.

\section{Authors' contributions}

FACC, DAC and LHJ conceived and designed the study and critically revised the manuscript. DAC AND LHJ performed the experiment, analyzed the data and drafted the manuscript. DAC, LHJ, FACC and BCN helped in data analysis and manuscript revision. DAC, LHJ, KJLM, BCN, PAAB, BBCE, MMA, MNB AND JPS helped in study implementation. All authors read and approved the final manuscript.

\section{Funding}

This study was jointly supported by Foundation Oswaldo Cruz (FIOCRUZ) and Coordination of Superior Level Staff Improvement (CAPES) cod 001 to DA

Calegar. The funders had no role in study design, data collection and analysis, decision to publish, or preparation of the manuscript. 


\section{Availability of data and materials}

The datasets analyzed during the present study are available from the corresponding author upon reasonable request. All sequence files are available from the GenBank database under accession numbers MW026735-MW026794.

\section{Declarations}

\section{Ethics approval and consent to participate}

The study was approved by the Research Ethics Committee (license CAAE 12125713.5.0000.5248) of the Oswaldo Cruz Institute, Fiocruz. All subjects provided written informed consent, and the parent or legal guardian of all children included in this study provided written informed consent on their behalf.

\section{Consent for publication}

Not applicable.

\section{Competing interests}

The authors declare that they have no competing interests.

\section{Author details}

${ }^{1}$ Laboratório de Epidemiologia e Sistemática Molecular, Instituto Oswaldo Cruz, Fundação Oswaldo Cruz, Rio de Janeiro, RJ, Brazil. ${ }^{2}$ Centro/Norte, Escritório Técnico Regional - Fundação Oswaldo Cruz, Piauí, Rua Magalhães Filho, 519, Teresina, Piauí, Brazil. ${ }^{3}$ Laboratório de Biologia e Parasitologia de Mamíferos Silvestres Reservatórios, Instituto Oswaldo Cruz, Fundação Oswaldo Cruz, Rio de Janeiro, RJ, Brazil. ${ }^{4}$ Faculdade de Medicina de Petrópolis (FMP)/ Faculdade Arthur Sá Earp Neto (FASE), Rua Machado Fagundes, 326, Cascatinha, Petrópolis, Rio de Janeiro, Brazil. ${ }^{5}$ Faculdade de Farmácia, Universidade Federal de Juiz de Fora, Rua José Lourenço Kelmer, s/n - Campus Universitário, Bairro São Pedro, Juiz de Fora, Minas Gerais, Brazil.

Received: 1 December 2020 Accepted: 5 March 2021

Published online: 17 March 2021

\section{References}

1. Stanley SL Jr. Amoebiasis. Lancet. 2003;361(9362):1025-34.

2. Kantor M, Abrantes A, Estevez A, Schiller A, Torrent J, Gascon J, et al. Entamoeba histolytica: updates in clinical manifestation, pathogenesis, and vaccine development. Can J Gastroenterol Hepatol. 2018;2018:4601420.

3. Oliveira FM, Neumann E, Gomes MA, Caliari MV. Entamoeba dispar: Could it be pathogenic. Trop Parasitol. 2015;5(1):9-14.

4. Khairnar K, Parija SC. A novel nested multiplex polymerase chain reaction (PCR) assay for differential detection of Entamoeba histolytica, E. moshkovskii and E. dispar DNA in stool samples. BMC Microbiol. 2007;7:47.

5. Costa CA, Brito KN, Gomes MA, Caliari MV. Histopathological and immunohistochemical study of the hepatic lesions experimentally induced by Entamoeba dispar. Eur J Histochem. 2010;54(3):e39.

6. Feng M, Pandey $\mathrm{K}$, Yanagi T, Wang T, Putaporntip C, Jongwutiwes $\mathrm{S}$, et al. Prevalence and genotypic diversity of Entamoeba species in inhabitants in Kathmandu, Nepal. Parasitol Res. 2018;117(8):2467-72.

7. Zavala GA, García OP, Camacho M, Ronquillo D, Campos-Ponce M, Doak $C$, et al. Intestinal parasites: associations with intestinal and systemic inflammation. Parasite Immunol. 2018:40(4):e12518.

8. Boeke CE, Mora-Plazas M, Forero Y, Villamor E. Intestinal protozoan infections in relation to nutritional status and gastrointestinal morbidity in Colombian school children. J Trop Pediatr. 2010;56(5):299-306.

9. Stensvold CR, Lebbad M, Victory EL, Verweij JJ, Tannich E, Alfellani M, et al. Increased sampling reveals novel lineages of Entamoeba: consequences of genetic diversity and host specificity for taxonomy and molecular detection. Protist. 2011;162(3):525-41.

10. Verweij JJ, Laeijendecker D, Brienen EA, van Lieshout L, Polderman AM. Detection and identification of Entamoeba species in stool samples by a reverse line hybridization assay. J Clin Microbiol. 2003;41(11):5041-5.

11. Clark CG, Kaffashian F, Tawari B, Windsor JJ, Twigg-Flesner A, DaviesMorel MCG, et al. New insights into the phylogeny of Entamoeba species provided by analysis of four new small-subunit rRNA genes. Int I Syst Evol Microbiol. 2006;56(Pt 9):2235-9.

12. Young KH, Bullock SL, Melvin DM, Spruill CL. Ethyl acetate as a substitute for diethyl ether the formalin-ether sedimentation technique. J Clin Microbiol. 1979;10(6):852-3.

13. Verweij JJ, Polderman AM, Clark CG. Genetic variation among human isolates of uninucleated cyst-producing Entamoeba species. J Clin Microbiol. 2001;39(4):1644-6.

14. Dunn IS, Blattner FR. Charons 36 to 40: Multi-enzyme, high capacity, recombination deficient replacement vectors with polylinkers and polystuffers. Nucleic Acids Res. 1987;15(6):2677-98.

15. Hall TA. BioEdit: a user-friendly biological sequence alignment editor and analysis program for windows 95/98/NT. Nucleic Acids Symp Ser. 1999:41:95-8.

16. Kumar S, Stecher G, Li M, Knyaz C, Tamura K. MEGA X: molecular evolutionary genetics analysis across computing platforms. Mol Biol Evol. 2018;35(6):1547-9.

17. Bandelt HJ, Forster $P$, Röhl A. Median-joining networks for inferring intraspecific phylogenies. Mol Biol Evol. 1999;16(1):37-48.

18. Rozas J, Ferrer-Mata A, Sánchez-DelBarrio JC, Guirao-Rico S, Librado P, Ramos-Onsins SE, Sánchez-Gracia A. DnaSP 6: DNA sequence polymorphism analysis of large data sets. Mol Biol Evol. 2017;34(12):3299-302.

19. Excoffier $L$, Lischer HEL. Arlequin suite ver 3.5, a new series of programs to perform population genetics analyses under linux and windows. Mol Eco Resour. 2010;10(3):564-7.

20. Gutiérrez-Jiménez J, Luna-Cázares LM, Cruz LM, De Aquino-López JA, Sandoval-Gómez D, León-Ortiz AT, et al. Children from a rural region in The Chiapas Highlands, Mexico, show an increased risk of stunting and intestinal parasitosis when compared with urban children. Bol Med Hosp Infant Mex. 2019;76(1):18-26.

21. Calegar DA, Nunes BC, Monteiro KJ, Santos JP, Keiko HT, Gomes TF, et al. Frequency and molecular characterisation of Entamoeba histolytica, Entamoeba dispar, Entamoeba moshkovskii, and Entamoeba hartmanni in the context of water scarcity in northeastern Brazil. Mem Inst Oswaldo Cruz. 2016;111(2):114-9.

22. Tarleton JL, Haque R, Mondal D, Shu J, Farr BM, Petri WA Jr. Cognitive effects of diarrhea, malnutrition, and Entamoeba histolytica infection on school age children in Dhaka, Bangladesh. Am J Trop Med Hyg. 2006;74(3):475-81.

23. Jacob AS, Busby EJ, Levy AD, Komm N, Clark CG. Expanding the Entamoeba Universe: new hosts yield novel ribosomal lineages. J Eukaryot Microbiol. 2016:63:69-78.

24. Graffeo R, Archibusacci CM, Soldini S, Romano L, Masucci L. Entamoeba dispar: a rare case of enteritis in a patient living in a nonendemic area. Case Rep Gastrointest Med. 2014;2014:498058.

25. Ximénez C, Cerritos R, Rojas L, Dolabella S, Morán P, Shibayama M, et al. Human amebiasis: breaking the paradigm? Int J Environ Res Public Health. 2010;7(3):1105-20.

26. Gomes TDS, Garcia MC, Cunha FDS, de Macedo HW, Peralta JM, Peralta RHS. Differential diagnosis of Entamoeba spp. in clinical stool samples using SYBR green real-time polymerase chain reaction. Sci World J. 2014;12:645084e

27. Silva MT, Santana JV, Bragagnoli G, Marinho AM, Malagueño E. Prevalence of Entamoeba histolytica/Entamoeba dispar in the city of Campina Grande, in northeastern Brazil. Rev Inst Med Trop Sao Paulo. 2014;56(5):451-4.

28. Yimer M, Zenebe Y, Mulu W, Abera B, Saugar JM. Molecular prevalence of Entamoeba histolytica/dispar infection among patients attending four health centres in north-west Ethiopia. Trop Doct. 2017;47(1):11-5.

29. Soares NM, Azevedo HC, Pacheco FTF, de Souza JN, Del-Rei RP, Teixeira MCA, et al. A cross-sectional study of Entamoeba histolytical dispar/moshkovskii complex in Salvador, Bahia, Brazil. Biomed Res Int. 2019:2019:7523670.

30. Dourado A, Maciel A, Aca IS. Occurrence of Entamoeba histolytica/Entamoeba dispar in ambulatory patients of Recife. PE Rev Soc Bras Med Trop. 2006;39(4):388-9

31. Santos FL, Gonçalves MS, Soares NM. Validation and utilization of PCR for differential diagnosis and prevalence determination of Entamoeba histolytica/Entamoeba dispar in Salvador City, Brazil. Braz J Infect Dis. 2011;15(2):119-25.

32. Tachibana H, Yanagi T, Pandey K, Cheng XJ, Kobayashi S, Sherchand JB, et al. An Entamoeba sp. strain isolated from rhesus monkey is virulent but 
genetically different from Entamoeba histolytica. Mol Biochem Parasitol. 2007;153(2):107-14.

33. Suzuki J, Kobayashi S, Imada M, Tolba ME, Takeuchi T. Characterization of a novel Entamoeba histolytica strain from Burkina Faso, Africa, possessing a unique hexokinase-2 gene. Parasite. 2011;18(4):287-94.

34. Kocherscheidt L, Agossou A, Gantin RG, Hamm DM, Banla M, Soboslay PT. Cytokine and chemokine responses in adults, newborns and children exposed to Entamoeba histolytica/dispar, Onchocerca volvulus and Plasmodium falciparum. Pediatr Allergy Immunol. 2010;21 (4 Pt 2):e756-63.

35. Zermeño V, Ximénez C, Morán P, Valadez A, Valenzuela O, Rascón E, et al. Worldwide genealogy of Entamoeba histolytica: an overview to understand haplotype distribution and infection outcome. Infect Genet Evol. 2013;17:243-52

36. Van Den Broucke S, Verschueren J, Van Esbroeck M, Bottieau E, Van den Ende J. Clinical and microscopic predictors of Entamoeba histolytica intestinal infection in travelers and migrants diagnosed with Entamoeba histolytica/dispar infection. PLoS Negl Trop Dis. 2018;12(10):e0006892.

37. Petri WA Jr, Haque R, et al. Entamoeba species, including amebiasis. In: Bennett JE, Dolin R, Blaser MJ, et al., editors. Mandell, Douglas, and Bennett's principles and practice of infectious diseases, vol. 2. 9th ed. Philadelphia: Elsevier/Saunders; 2019. p. 3422-5.

38. Yanagawa Y, Nagata N, Yagita K, Watanabe K, Okubo H, Kikuchi Y, et al. Clinical features and gut microbiome of asymptomatic Entamoeba histolytica infection. Clin Infect Dis. 2020. https://doi.org/10.1093/cid/ciaa820

39. Silberman JD, Clark CG, Diamond LS, Sogin ML. Phylogeny of the genera Entamoeba and Endolimax as deduced from small-subunit ribosomal RNA sequences. Mol Biol Evol. 1999;16(12):1740-51.

40. Chavatte JM, Jureen R. Incidental detection of Cyclospora cayetanensis during general health screening: a case study from Singapore. J Trop Dis. 2016;4(5):224

41. Clark CG, Diamond LS. Intraspecific variation and phylogenetic relationships in the genus Entamoeba as revealed by riboprinting. J Eukaryot Microbiol. 1997:44(2):142-54.

42. Elsheikha HM, Regan CS, Clark CG. Novel Entamoeba findings in nonhuman primates. Trends Parasitol. 2018;34(4):283-94.

43. Kobayashi S, Suzuki J, Takeuchi T. Establishment of a continuous culture system for Entamoeba muris and analysis of the small subunit rRNA gene. Parasite. 2009;16(2):135-9.

44. Nolan MJ, Unger M, Yeap YT, Rogers E, Millet I, Harman K, et al. Molecular characterisation of protist parasites in human-habituated mountain gorillas (Gorilla beringei beringei), humans and livestock, from Bwindi impenetrable National Park, Uganda. Parasit Vectors. 2017;10(1):340.
45. Carvalho-Costa FA, Gonçalves AQ, Lassance SL, Silva Neto LM, Salmazo CA, Bóia MN. Giardia lamblia and other intestinal parasitic infections and their relationships with nutritional status in children in Brazilian Amazon. Rev Inst Med Trop Sao Paulo. 2007:49(3):147-53.

46. Bóia MN, Carvalho-Costa FA, Sodré FC, Porras-Pedroza BE, Faria EC, Magalhães GAP, et al. Tuberculosis and intestinal parasitism among indigenous people in the Brazilian Amazon region. Rev Saude Publica. 2009;43(1):176-8. Erratum in: Rev Saude Publica. 2009;43(5):905. Coura, José Rodrigues [removed].

47. Coronato-Nunes B, Calegar DA, Monteiro KJL, Hubert-Jaeger L, Reis ERC, Xavier SCDC, et al. Giardia intestinalis infection associated with malnutrition in children living in northeastern Brazil. J Infect Dev Ctries. 2017;11(7):563-70.

48. Dias AP, Calegar D, Carvalho-Costa FA, Alencar MFL, Ignacio CF, da Silva $M E C$, et al. Assessing the influence of water management and rainfall seasonality on water quality and intestinal parasitism in rural Northeastern Brazil. J Trop Med. 2018;2018:8159354.

49. Calegar DA, Monteiro KJL, Gonçalves AB, Boia MN, Jaeger LH, Nunes BC, et al. Infections with Giardia duodenalis and Entamoeba histolytica/Entamoeba dispar as Hidden and Prevalent Conditions in Periurban Communities in the State of Rio de Janeiro Brazil. J Trop Med. 2020;2020:3134849.

50. Brasil. Plano integrado de ações estratégicas de eliminação da hanseníase, filariose, esquistossomose e oncocercose como problema de saúde pública, tracoma como causa de cegueira e controle das geohelmintíases: plano de ação 2011-2015 / Ministério da Saúde, Secretaria de Vigilância em Saúde, Departamento de Vigilância em Doenças Transmissíveis. - 1. ed., 1. reimpr. Brasília: Ministério da Saúde, 2013. p.100.

51. Turkeltaub JA, McCarty TR 3rd, Hotez PJ. The intestinal protozoa: emerging impact on global health and development. Curr Opin Gastroenterol. 2015;31(1):38-44.

52. Brasil. Ministério da Saúde: Guia prático para operacionalizacão da Campanha Nacional de Hanseníase, Verminoses, Tracoma e Esquistossomose. Brasil. 2016, p. 8-35.

\section{Publisher's Note}

Springer Nature remains neutral with regard to jurisdictional claims in published maps and institutional affiliations.
Ready to submit your research? Choose BMC and benefit from:

- fast, convenient online submission

- thorough peer review by experienced researchers in your field

- rapid publication on acceptance

- support for research data, including large and complex data types

- gold Open Access which fosters wider collaboration and increased citations

- maximum visibility for your research: over $100 \mathrm{M}$ website views per year

At BMC, research is always in progress.

Learn more biomedcentral.com/submissions 